\title{
Acute myocardial ischemia associated with hiccups
}

\author{
Jonathon Broughton MD, Aditya Sharma MD
}

Cite as: CMAJ 2019 July 2;191:E738. doi: 10.1503/cmaj.181285

A 59-year-old man developed a bout of hiccups during hospital admission for septic arthritis of the metatarsal joint. Although the patient was asymptomatic otherwise, a cardiac workup was initiated because of newly diagnosed diabetes mellitus and hypertension. Compared with an electrocardiogram (ECG) from the previous day (Appendix 1, available at www.cmaj. ca/lookup/suppl/doi:10.1503/cmaj.181285/-/ DC1), a new Wellens type B pattern (deeply inverted precordial T waves) (Figure 1) was found, which was associated with a troponin T level of $146 \mu \mathrm{g} / \mathrm{L}$ that increased to $152 \mu \mathrm{g} / \mathrm{L}$ in 2 hours (normal < $3 \mu \mathrm{g} / \mathrm{L}$ ). The patient was treated for possible acute coronary syndrome and his hiccups resolved, with normalization of his ECG.

Four days later, a culprit $70 \%$ lesion in the mid-left anterior descending coronary artery was found during angiography and treated with a drug-eluting stent. Low-grade disease in multiple vessels was treated medically. An echocardiogram showed a normal ejection fraction without evidence of regional wall abnormalities. The patient was later discharged without recurrence of hiccups.

More than 100 discrete etiologies may cause hiccups, including myocardial infarction. ${ }^{1}$ The pathophysiology is complex and incompletely understood, but it is likely related to stimulation of a reflex arc involving thoracic segments of the sympathetic chain, and the phrenic and vagus nerves. In myocardial infarction, this reflex is activated, causing diaphragmatic contractions to occur, and is followed by glottic closure, causing the "hic" sound. ${ }^{1}$ We found only a limited number of cases of myocardial infarctions presenting with hiccups as the sole symptom; all have occurred in men with hypertension and diabetes. ${ }^{2,3}$ In patients at risk for ischemic heart disease, hiccups may be the sole complaint in cases of myocardial ischemia, and simple, low-cost investigations such as an ECG could be considered in the workup of these patients.

\section{References}

1. Kolodzik PW, Eilers MA. Hiccups (singultus): review and approach to management. Ann Emerg Med 1991;20:565-73.

2. Davenport J, Duong M, Lanoix R. Hiccups as the only symptom of non-STsegment elevation myocardial infarction. Am J Emerg Med 2012;30:266.e1-2.

3. Shaikh N, Raj R, Movva S, et al. Persistent hiccups as the only presenting symptom of ST elevation myocardial infarction. Case Rep Cardiol 2018;2018: 7237454.

\section{Competing interests: None declared.}

This article has been peer reviewed.

The authors have obtained patient consent.

Affiliations: Departments of Emergency Medicine (Broughton) and Internal Medicine (Sharma), Max Rady College of Medicine, University of Manitoba, Winnipeg, Man.

Correspondence to: Jonathon Broughton, umbrougj@myumanitoba.ca 